paediatricians, psychiatrists, and social workers. The parents should, of course, always be put into touch with the appropriate voluntary organization (the National Society for Autistic Children).

\section{Summary}

A survey of children aged 8,9 , and 10 resident in the former County of Middlesex on 1 January 1964 showed that 4.5 per 10,000 had "autistic conditions of early childhood." This means that there are about twice as many autistic children in the country as there are blind children. There was a raised male-female ratio but no special birth order. Autistic children were more likely to have suffered from complications during pregnancy and delivery than their siblings, and one-half had marked delay in motor milestones. It was confirmed that the parents of autistic children (particularly those in the " nuclear group") were likely to be above average in educational attainmem, occupational level, and intelligence. There was no evidence for a genetic or clinical relationship between early childhood autism and schizophrenia. Clinical and educational services still leave much to be desired.

\section{RBFERENCES}

Barton, R. (1959). Institutional Neurosis. Bristol

Creak, M., and Ini, S. (1960). F. Child Psychol., 1, 156.

Elgar, S. (1966). In Early Childhood Autism, edited by J. K. Wing, p. 205. Oxford.

Heeley, A. F., and Roberts, G. E. (1965). Develop. Med. Child Neurol., $7,46$.

Humphrey, G., and Humphrey, M. (1932). Translation of The Wild Boy of Aveyron, by J. M. G. Itard. New York.

Ingram, T. T. S. (1960). In Child Neurology and Cerebral Palsy edited by M. C. O. Bax, E. Clayton Jones, and R. C. Mac Keith. Oxford. Kanner, 'L. (1943). Nerv. Child, 2, 217.

- (1957). Child Psychiatry, 3rd ed. Springfield, Illinois.

Lotter, V. (19662). Soc. Psychiat., 1, 124, 163.

(1966b). In Early Childhood Autism, edited by J. K. Wing, p. 241. Oxford.

Lovaas, O. I. (1966). Ibid., p. 115.

Malzberg, B. (1954). Amer.

Pronovost, W., Wakstein, M. P., and Wakstein, D. J. (1966). Exceptional Children, 33, 19.

Rimland, B. (1964). Infantile Autism. New York.

Rutter, M. L. (1965). In Children with Communication Problems, edited by A. W. Franklin. London.

(1966). In Early Childhood Autism, edited by J. K. Wing, p. 51. Oxford.

Tizard, J.; and Grad, J. C. (1961). The Mentally Hendicapped and thetr Pamilies. London.

Wing, J. K. (1962). Brit. F. soc. clin. Psychol., 1, 38 Wolf, S., and Chess, S. (1964). Acta psychriat. scamd., 40, 438.

\title{
Evolution of the Ventilatory Capacity in Chronic Bronchitis
}

\author{
PETER HOWARD,* M.A., B.M., M.R.C.P.
}

Brit. med. F., 1967, 3, 392-395

The forced expiratory volume (F.E.V.) and its derivative the indirect maximum breathing capacity (M.B.C.) are used as indices of airways obstruction in patients with chronic obstructive airways disease. Prevalence studies of particular populations or groups of normal subjects have shown the F.E.V. to decline linearly with age. It is agreed that the ventilatory capacity declines further with progression of obstructive airways disease, but little information is yet available about the rate and mode of decline, particularly in relation to the phase of illness. The results of a long-term follow-up study are now reported in which the changes in the F.E.V. ${ }_{0.75}$ have been carefully observed in a group of patients with established chronic obstructive airways disease attending an outpatient clinic. Particular attention has been paid to the long-term changes in individual patients and also to the effects of acute exacerbations of symptoms. It was hoped that the information might lead to a better understanding of the progress of airways obstruction, which is generally believed to be the chief cause of disability in chronic bronchitis.

\section{Methods of Study}

A study was made of 112 men and 13 women attending the clinic on account of frequent exacerbations of chest illness or breathlessness, usually the latter. Patients were included who had been followed regularly for at least two years, and this was the major criterion for admission to the study. In 1962 the patients answered the Medical Research Council (1960) short questionary on respiratory symptoms. All except two patients admitted to a productive cough, but a further 10 thought it occurred less often than on "most days for three months of the year" (grade 0 ). Of these 10 patients, five had attacks of bronchial asthma defined as sudden attacks of reversible severe

- Department of Medicine, University of Sheffield, the Royal Hospital, Sheffield 1. Present address: Department of Environmental Medicine, Johns Hopkins University, 615 North Wolfe Street, Baltimore, Maryland 21205, U.S.A. Requests for reprints to Sheffield. wheezing and breathlessness not associated with cardiovascular disease, one had hay-fever in the summer months, and four said they experienced frequent attacks of chest illnesses but denied the persistent production of sputum between attacks. Twenty-four patients said they produced sputum only in the mornings (grade 1) and 89 said that it was raised both in the mornings and throughout the day (grade 2). Therefore 123 patients could be classified as cases of chronic bronchitis of some severity (Medical Research Council, 1965). One hundred complained of breathlessness which limited them to their own pace on the level or of more severe disability, and only four denied any breathlessness. Of the 125 patients, 106 had suffered at least one attack of chest illness in the previous three years, but most of them experienced more frequent exacerbations than this. Three patients have developed congestive cardiac failure (cor pulmonale) during the period of observation.

The patients usually attend the clinic at monthly intervals or less in the winter-time and every two or three months in the summer. In the four years up to the end of 1965 the F.E.V. ${ }_{0.75}$ and the forced vital capacity (F.V.C.) were measured by means of a Poulton spirometer (McKerrow, McDermott, and Gilson, 1960) on each visit by one of three trained technicians. The F.E.V. was read directly off this instrument as the indirect M.B.C. in litres per minute. Five serial recordings were taken, the result being recorded as the mean of the best three readings. Before 1962 the same measurements were made annually with a Collins-Gaensler spirometer. From this machine the absolute F.E.V..$_{0.75}$ was measured, corrected for temperature, and then multiplied by 40 to derive the indirect M.B.C. In a comparison of the two instruments no significant difference was found between consecutive readings on the same patients $(t=16.6, \mathrm{P}<0.001)$.

Since the initiation of these studies the indirect M.B.C. has become a less popular method of recording this type of measurement. Thus in the analysis of the data the figures have been divided by 40 to convert them to the FE.V.0.75 as they were originally measured. Though formulae are available for 
converting F.E.V $\cdot_{0.75}$ to F.E.V. $\cdot_{1}$ this was not done in the present study, as such a conversion cannot easily be made without criticism (Pearson, Ashford, Brown, and Morgan, 1966). A regression of the change in F.E.V. $\cdot_{0.75}$ with time (in months) was calculated for each patient together with the standard deviation about the regression and the standard error of the slope. The connotation F.E.V. is used in this paper to represent F.E.V.0.75. Ninety-seven patients have been followed for more than four years and their measurements were taken with both instruments. In 28 patients the Poulton spirometer alone was used.

At each attendance the patient was examined and treatment prescribed. Most patients were treated with aerosol sprays of isoprenaline and/or adrenaline and atropine and an oral bronchodilator drug such as theophylline monoethanolamine, choline theophyllinate, or orciprenaline. Courses of tetracycline ( $1 \mathrm{~g}$. daily for seven days) or ampicillin ( $1 \mathrm{~g}$. daily for seven days) were dispensed to treat individual acute exacerbations of symptoms as they occurred. In the past three years extra courses have been given as reserve supplies for the patient to take himself as soon as he felt that a further exacerbation was developing. A small number of patients also received prednisolone for associated bronchial asthma or chlorothiazide diuretics for congestive heart failure.

\section{Results}

The mean age of the patients was 60.7 (S.D. $= \pm 9.86)$ years and Table I shows the age distribution. The mean period of follow-up was 7.1 years (range 2-13 years) and the mean initial F.E.V. 1.2 (S.D. $= \pm 0.165$ ) litres. Fig. 1 shows the distribution of the initial F.E.V. The regression coefficients were expressed in litres per year, and only four out of the 125 patients had a positive regression coefficient. The mean regres- sion coefficient for the whole group was -0.0834 (S.D. $= \pm$ 0.0667 ) litre per year. Fig. 2 shows the distribution. The mean standard deviation about this slope was \pm 0.162 litre and the mean standard error of the slope \pm 0.0221 litre per year. The death rate has been followed since 1962 , and up to the end of 196513 patients had died. Their mean age at death was 64.7 years and their mean regression coefficient -0.0930 litre per year, values which were slightly larger than those of the group as a whole.

TABLE I.-Age Distribution of the 125 Patients

\begin{tabular}{|c|c|c|c|c|c|c|}
\hline $\begin{array}{l}\text { Age in } 1965 \ldots \\
\text { No. of patients }\end{array}$ & .. & $\begin{array}{c}<39 \\
5\end{array}$ & $\begin{array}{c}40-49 \\
7\end{array}$ & $\underset{33}{50-59}$ & $\begin{array}{c}60-69 \\
62\end{array}$ & $\begin{array}{c}70-79 \\
18\end{array}$ \\
\hline
\end{tabular}

The regression coefficients were plotted against age in 1965, the mean F.E.V. (calculated from the sum of all measurements divided by the number of measurements on each individual), and the years of follow-up. A statistically significant regression was obtained with age in $1965 \quad(t=2.57$, $\mathrm{P}<0.02)$ and with the mean F.E.V. $(t=4.95, \mathrm{P}<0.001)$. The regression equations were:

$$
\begin{aligned}
& y=-0.00154 \text { age }+0.0101 \\
& y=-0.0648 \text { mean F.E.V. }-0.0308
\end{aligned}
$$

The regression coefficients were plotted on the ordinate. Thus the rate of fall of ventilatory capacity showed a small decline with age in this particular group of hospital patients. The rate of fall was also related to the mean F.E.V. The mean point was used rather than the initial F.E.V. as the use of the latter is apt to give spurious correlations (Oldham, 1962). The mean F.E.V. was not related to age $(t=0.6, \mathrm{P}>0.6)$ and was therefore an unlikely explanation of the age effect. Fig. 3 shows the plot of regression coefficient against years of follow-up, for which a regression was not calculated on account of the changing
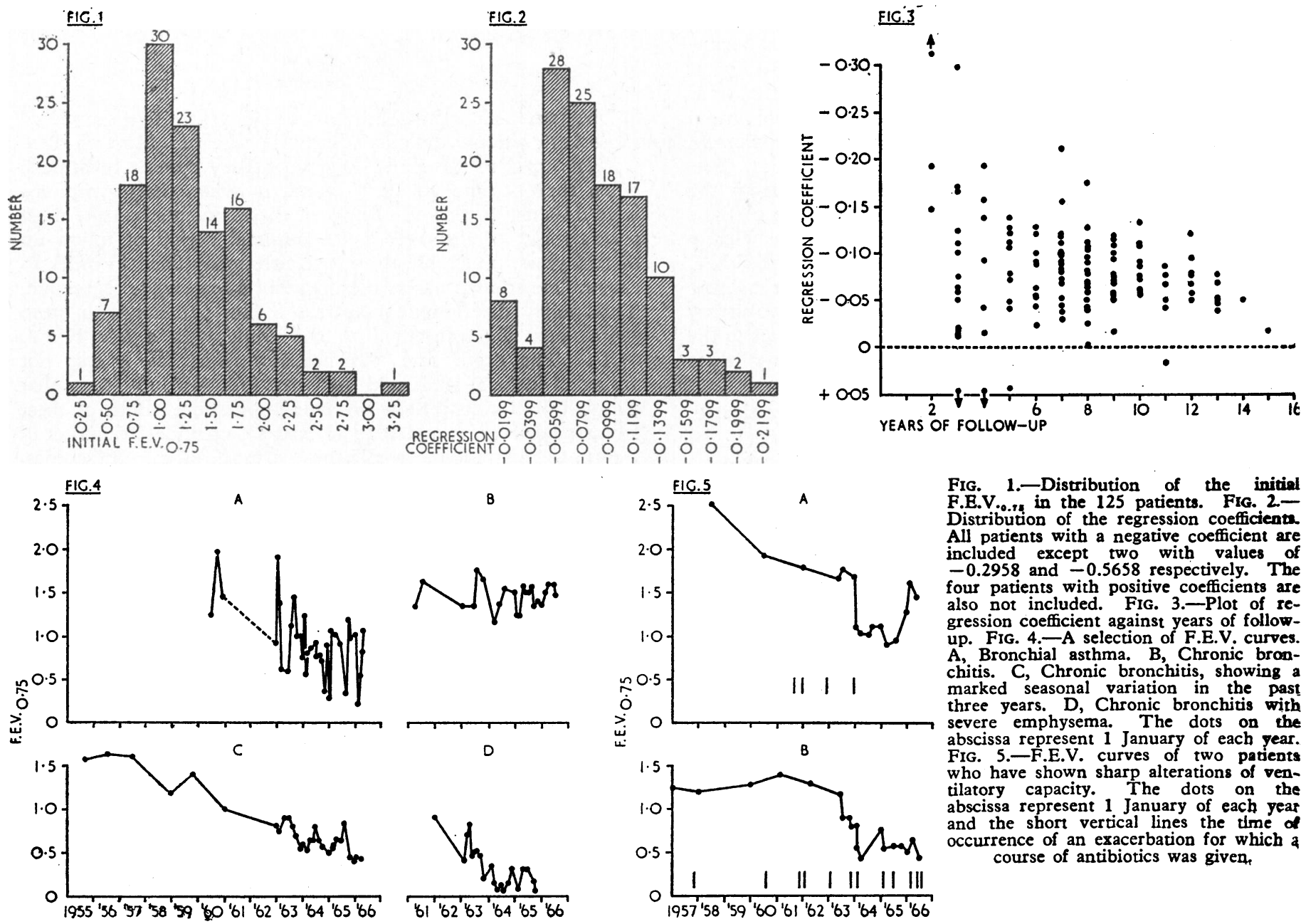

FIG. 1.-Distribution of the initial F.E.V.0.r, in the 125 patients. Frg. 2Distribution of the regression coefficienta. All patients with a negative coefficient are included except two with values of included except two with values of
-0.2958 and -0.5658 respectively. The four patients with positive coefficients are also not included. FIG. 3.-Plot of regression coefficient against years of followup. FIG. 4.-A selection of F.E.V. curves. chitis. C, Chronic bronchitis, showing a marked seasonal variation in the past three years. D, Chronic bronchitis with severe emphysema The dots on the abscissa represent 1 January of each eear. abscissa represent 1 January of each year. FIG. 5.-F.E.V. curves of two partents who have shown sharp alterations of ventilatory capacity. The dots on the and the short vertical lines the time of accurrence of an exacerbation for which a course of antibiotics was given. 
variance. The variance would be expected to be higher in those followed for only a short period, simply on account of the smaller number of observations possible, but also because of the tendency for those with higher rates of decline of ventilatory capacity to die or leave the clinic after being followed for only short periods. This may also be a factor in the explanation of the reduced rate of fall of ventilatory capacity with increasing age.

Inspection of the individual curves, particularly from the past four years when more measurements were available, revealed several points of interest. Seven patients (Fig. 4A) showed wide fluctuations of the F.E.V. All of these patients had bronchial asthma, and despite the large swings of F.E.V. many had large regression coefficients. In the remainder, forming the majority of patients and excluding those who improved, the F.E.V. declined at various rates with a variable fluctuation about the regression. Fig. 4B illustrates this picture. The "fluctuation" in 25 patients showed a seasonal variation, with troughs of low F.E.V. appearing in the winter months and the peak values in the summer (Fig. 4C). In half of the total number of patients no specific pattern to the variations could be discerned (Fig. 4D), but their amplitude remained relatively constant in any individual.

Disregarding the seasonal and spontaneous fluctuations, the rate of decline of F.E.V. in any one patient tended to remain constant for long periods, in some throughout the whole of the period of their observation. For example, in 19 out of 28 patients who had been followed for more than 10 years a straight line could easily be drawn by eye through the values obtained throughout the whole period. However, in a number of cases, excluding the "asthmatic" curves, there occurred sharp falls of F.E.V., arbitrarily defined as a loss of F.E.V. within six months or less, greater than two standard deviations from the regression. Twenty-one such incidents have occurred in 19 patients during the past four years. Fig. 5 gives two examples. Seven recovered completely within a year, usually within three months, three recovered between one and two years (Fig. 5A), four made a partial recovery, and in seven there was no recovery at all. The curves of the last-mentioned group thus showed a downward step, and the path of the regression usually intersected the step some way about its mid-point. The ruling of a departure by two standard deviations from the regression had to be relaxed on this account in some of these cases, but in all a step in the function curve was clearly visible. Fig. $5 \mathrm{~B}$ was such a case. The pattern of the F.E.V. curve has continued after the sharp fall in the same manner as before. The patients showing the sharp falls of ventilatory capacity did not differ clinically, as judged by the replies to the M.R.C. questionary, from those who did not show these changes.

The cause of the 21 sharp falls of function was investigated, and Table II shows the various illnesses which could be associated with them in time. In only 10 patients could an acute exacerbation, however mild, be implicated, and in six no change in clinical status had apparently occurred. Some even maintained that they were as well as they had ever been. Though the sharp falls of function appeared slightly more often in the winter months (Table III), there was no significant seasonal factor. Smoking habits were not recorded in detail at the time of occurrence, but appeared to be a factor in that replies from the questionaries completed in 1962 (Table IV), indicated that those patients showing the sharp functional alterations were more persistent smokers than those who did not have these changes.

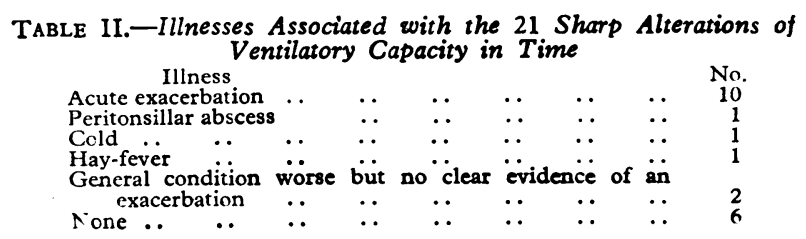

TABLE III.-Seasonal Occurrence of the 21 Sharp Alterations of Ventilatory Capacity

\begin{tabular}{|c|c|c|c|c|c|c|c|c|}
\hline $\begin{array}{l}\text { Month } \\
\text { January } \\
\text { February } \\
\text { March . . } \\
\text { April } \quad .\end{array}$ & $\begin{array}{l}\because \\
\because \\
\cdots\end{array}$ & $\begin{array}{r}\text { No. } \\
1 \\
2 \\
2 \\
4\end{array}$ & 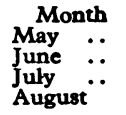 & $\because \ddot{ }$ & $\begin{array}{r}\text { No. } \\
\begin{array}{r}2 \\
3\end{array}\end{array}$ & $\begin{array}{l}\text { Month } \\
\text { September } \\
\text { October .. } \\
\text { November } \\
\text { December }\end{array}$ & $\because \because$ & $\begin{array}{r}\text { No. } \\
2 \\
\frac{2}{3}\end{array}$ \\
\hline
\end{tabular}

TABLE IV.- Smoking Habits in 1962 of Patients Who Subsequently Had Sharp Alterations of Ventilatory Capacity Compared with Smoking Habits of Those Who Did Not Exhibit These Changes. Figures in Parentheses are Percentages

\begin{tabular}{|c|c|c|c|c|c|c|}
\hline \multirow{2}{*}{$\begin{array}{l}\text { Patient } \\
\text { Group }\end{array}$} & \multirow[b]{2}{*}{ No. } & \multicolumn{2}{|c|}{ Cigarette Smokers } & \multirow{2}{*}{ Smokers } & \multirow{2}{*}{$\begin{array}{c}\text { Pipe } \\
\text { Smokers }\end{array}$} & \multirow{2}{*}{$\begin{array}{l}\text { Non- } \\
\text { Smokers }\end{array}$} \\
\hline & & $\stackrel{0-14}{\text { Daily }}$ & $\begin{array}{l}15+ \\
\text { Daily }\end{array}$ & & & \\
\hline $\begin{array}{l}\text { Patients with sharp falls } \\
\text { Remaining patients }\end{array}$ & $\begin{array}{l}19 \\
106\end{array}$ & $\begin{array}{l}11(58) \\
34(33)\end{array}$ & $\begin{array}{r}4(21) \\
11(10)\end{array}$ & $\begin{array}{r}3(16) \\
43(41)\end{array}$ & $\overline{8(7)}$ & $\begin{aligned} & 1(5) \\
& 10(9)\end{aligned}$ \\
\hline Total & 125 & $45(36)$ & $15(12)$ & $46(37)$ & $8(6)$ & $11(9)$ \\
\hline
\end{tabular}

The relation between acute exacerbations of symptoms and the rate of fall of the F.E.V. was examined further. In each patient the time of occurrence during the past four years of acute exacerbations for which antibiotics were given was marked on the F.E.V. curve. The majority showed no more than a minor fall of the F.E.V. The regression coefficients were plotted against the number of courses of antibiotics prescribed per year in the past four years for all patients, and the relation was just significant at the $5 \%$ level of probability $(t=2.04$, $\mathrm{P}<0.05$ ).

Finally, the change in F.E.V. was compared with the change in F.V.C. in those patients showing the sharp falls of function. F.E.V./F.V.C. and F.V.C. were plotted against time, and in 16 patients out of the 19 both fell, indicating that the decline in F.E.V. could be partly accounted for by a fall in vital capacity. In a number of the remaining patients picked at random the same trend was evident throughout the period of follow-up.

\section{Discussion}

The patients in this study are a highly selective sample of those with chronic obstructive airways disease. Most of them were referred to the clinic only when they became breathless, when they became unable to work, or when their symptoms were difficult to control. Many of these patients had the most severe forms of the disease. A minimal period of follow-up of two years, preferably three, was arbitrarily fixed in order to accumulate enough observations to plot a reasonable regression. This policy discriminated against a few patients with steep regressions who presented to the clinic with a low F.E.V. $(<1)$. The death rate was underestimated, as it was not recorded before 1962 and patients followed up from that period would constitute a survivor population. Both of these factors, however, would tend to lead to an underestimation of the mean regression coefficient. Despite these difficulties, several important features are shown. Firstly, the average rate of fall of ventilatory capacity is very much higher than other figures reported so far; secondly, the rate of decline is very variable even in patients with established disease, some patients having particularly steep rates of fall; and, thirdly, though most patients appear to lose function in a reasonably linear manner, a number exhibit sharp drops which do not recover. These points are discussed below in more detail.

The progressive deterioration of function occurred in all but four patients. It could not be accounted for by the ageing of the population, and it continued despite careful symptomatic treatment administered in the clinic. The mean regression coefficient of -0.0834 litre per year is larger than other reported figures. Higgins and Oldham (1962), in a five-year follow-up of miners and non-miners in the Rhondda Fach, found an overall loss of $\mathbf{0 . 0 4 7 2}$ litre per year. Age correlations from prevalence studies have been used to calculate the rate of deterioration of ventilatory capacity. Baldwin, Cournand, and 
Richards (1948) thus found a fall of 0.013 litre per year (calculated from the direct M.B.C.), Kory, Callahan, Boren, and Syner (1961) a fall of 0.025 litre per year (calculated from F.E.V.1), and Ferris, Anderson, and Zickmantel (1965) a fall of 0.024 litre per year (also calculated from F.E.V..), all in healthy males after standardizing for body size. Preliminary figures from a companion study of a slightly younger male group of 142 workers from a Sheffield steel and chemical plant followed since 1956, using the same spirometers, reveal a mean regression coefficient of the order of -0.03 litre per year up to the end of 1965. The expression of the decline in ventilatory capacity as a regression coefficient is a useful index of the overall decline and one measure of the severity of the disease.

Though a detailed follow-up of the ventilatory tests has been in progress for only four years, it would appear that the path of the mean F.E.V. does fall in a reasonably linear manner in many patients for periods of at least several years. The slope is very variable, but sufficient clinical and physiological information is not yet available to compare and contrast patients with differing rates of deterioration of ventilatory capacity. The sharp alterations of ventilatory capacity seen in some patients were surprisingly infrequent, as it was expected that the exacerbations of the disease would have had a much greater effect on the F.E.V. curve. It is true that in outpatient clinics attendances may have been missed at the peak of illness and some sharp falls therefore gone unnoted. However, many exacerbations were observed in the acute phase and most at some stage during recovery, and still significant decreases of F.E.V. were relatively infrequently found, and closer study is warranted.

The significance of the sharp falls of function that were observed cannot yet be fully evaluated. In particular, information is needed to determine how often they occur during the natural history of the disease, and whether they develop in persons with completely normal function. The findings suggest that chronic bronchitis is asseciated with some pathological process which is responsible for a steady erosion of ventilatory capacity, but that the same or a different process exacerbates the decline at certain times. Since a complete recovery of function was observed in only half of the instances where steep falls occurred, the latter must contribute to at least part of the overall decline.

Several factors are thought to play a part in the cause of chronic bronchitis, such as smoking, atmospheric pollution, and bronchial infection. Tobacco consumption has not been studied in detail, but it was clear from the replies given to the questionary in 1962 that those who subsequently showed the steep falls of ventilatory capacity were more persistent smokers than those who exhibited a steady deterioration. It is hoped, at a later date, to prepare a more detailed analysis of the relation between smoking habits and the decline of ventilatory capacity.

The significance of bronchial infection is difficult to assess. The acute exacerbations so characteristic of the disease have been attributed to bronchial infection on clinical grounds and by the isolation of pathogenic organisms such as Streptococcus pneumoniae and Haemophilus influenzae from the sputum. Pathologists looking at the terminal phases of the disease have suggested that bronchial infection plays an important part in the development of destructive lung changes (Leopold and Gough, 1957 ; Reid, 1961). In controlled trials of the prophylactic use of antibiotics the total period of disability from exacerbations has been found to be reduced but the number of exacerbations unaffected (Murdoch, Leckie, Downie, Swain, and Gould, 1959 ; Francis and Spicer, 1960 ; Francis, May and Spicer, 1964). This suggests that the acute exacerbations are initiated by factors unrelated to bacterial infection but may be prolonged by its secondary effects.

Whatever the causes of the acute exacerbation, this study shows that the majority had very little effect on the individual F.E.V. curves but there was some correlation between the rate of deterioration of function and the number of courses of antibiotic prescribed. Though the establishment of a correlation does not prove a causal relation, it is possible that bronchial infection is a factor in the steady erosion of ventilatory capacity. But in a controlled trial of chemotherapy undertaken by the Medical Research Council (Fletcher, 1965 ; Medical Research Council, 1966) no difference was found in the deterioration of function between patients showing a large number of respiratory illnesses and frequent periods of mucopurulent sputum and those without these features. In a quarter of the patients in the present study who exhibited sharp falls of ventilatory capacity clinical evidence of a coincident exacerbation could not be obtained. Thus, although bacterial infection recognizable on clinical grounds and frequent exacerbations of disease may contribute, they do not seem to be essential to the decline of ventilatory capacity.

\section{Summary}

A follow-up study of the F.E.V.0.75 in 125 patients with chronic obstructive airways disease attending an outpatient clinic is presented. The mean age of the group in 1965 was 60.7 years and the mean period of follow-up 7.1 years. The mean rate of fall of F.E.V. expressed as a regression coefficient was 0.0834 litre per year and considerably greater than that so far reported in normal subjects or other populations.

In the past four years a detailed study has been made of all patients whose F.E.V. was measured on every attendance at the clinic. Several varieties of F.E.V. curves are described. The size of individual regression coefficients was very variable even in patients with severe disease. There was some relation between the size of the regression coefficient and the number of acute exacerbations of the disease requiring antibiotic therapy, but, in individual plots, acute chest illnesses in the majority had no more than a minor effect on the F.E.V. curve. Yet on 21 occasions in 19 patients in the past four years steep falls of the F.E.V. (a loss greater than two standard deviations from the regression occurring within six months or less) were observed. One-quarter of these episodes could not be associated with any chest illness, however mild, and in only half was a good recovery of function observed. These results are discussed in regard to the aetiology of obstructive airways disease.

I am grateful to Professor C. H. Stuart-Harris for his encouragement and constructive criticism of this work. I also thank Miss Victoria Home, who made most of the measurements of forced expiratory volume. This work was supported in part by grant No. H.E. 04775 from the National Heart Institute, U.S. Public Health Service, and in part by the Board of Governors of the United Sheffield Hospitals.

\section{REFERENCES}

Baldwin, E. de F., Cournand, A., and Richards, D. W. (1948). Medicine (Baltimore), 27, 243.

Ferris, B. G., Anderson, D. O., and Zickmantel, R. (1965). Amer. Rev. resp. Dis., 91, 252.

Fletcher, C. M. (1965). In Bronchitis 2. International Symposium held at Gröningen, 1964, edited by N. G. M. Orie and H. J. Sluiter. p. 372. Springfield, Illinois.

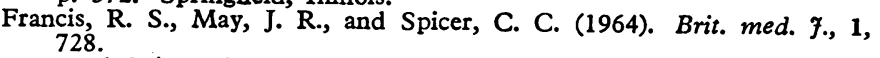

and Spicer, C. C. (1960). Ibid., 1, 297. Higgins, I. T. T., and Oldham, P. D. (1962). Brit. f. industr. Med., 19, Kory, R. C., Callahan, R., Boren, H. G., and Syner, J. C. (1961). Amer.

Leopold, J. G., and Gough, J. (1957). Thorax, 12, 219.

McKerrow, C. B., McDermott, M., and Gilson, J. C. (1960). Lancet, $1,149$.

Medical Research Council (1960). Brit. med. f., 2, 1665. (1965). Lancet, 1, 775 .

(1966). Brit. med. f., 1, 1317.

Murdoch, J. McC., Leckie, W. J. H., Downie, J., Swain, R. H. A., and Gould, J. C. (1959). Ibid., $2,1277$.

Oldham, P. D. (1962). F. chron. Dis., 15, 969.

Pearson, N. G., Ashford, J. R., Brown, S., and Morgan, D. C (1966). Amer. Rev. resp. Dis., 94, 64

Gröningen, 1960, In Bronchitis, International Symposium held at Gröningen, 1960, edited by N. G. M. Orie and H. J. Sluiter, p. 137.
Springfield, Illinois. 